\title{
Outer Membrane Protein III of Neisseria gonorrhoeae: Variations in Biological Properties of Antibodies Directed against Different Epitopes
}

\author{
By M. VIRJI,* K. ZAK AND J. E. HECKELS \\ Department of Microbiology, Southampton University Medical School, Southampton General \\ Hospital, South Academic Block, Tremona Road, Southampton SO9 4XY, UK
}

(Received 29 May 1987)

\begin{abstract}
Monoclonal antibodies (mAbs) have been raised to gonococcal outer membranes. A panel of six mAbs was identified by several criteria as reacting with outer membrane protein III (P.III). Competitive radioimmunoassays showed that the mAbs could be grouped into three pairs recognizing different epitopes on P.III. These epitopes are equally present on all pathogenic Neisseria. The mAbs demonstrated differing protective effects in model systems. Those directed against one epitope were particularly effective in protecting Chang conjunctiva epithelial cells against gonococcal challenge. mAbs against this epitope and another promoted complement-mediated bactericidal activity, while those directed against the third epitope were ineffective. Thus the biological effects of mAbs directed against P.III vary according to the epitope recognized.
\end{abstract}

\section{INTRODUCTION}

Outer membrane proteins of gonococci have been subject to considerable interest both with regard to their role in pathogenesis and as possible vaccine candidates. Three major proteins designated protein I, II and III (P.I, P.II and P.III) have been described (Swanson \& Heckels, 1980; McDade \& Johnston, 1980). P.I, the most abundant outer membrane protein, occurs in the membrane as a trimer (Newhall et al., 1980), functions as a porin (Douglas et al., 1981; Lynch et al., 1984) and interacts with host cell membranes in a way which may initiate gonococcal invasion (Blake, 1985). Although P.I is present in all strains, structural differences occur between strains which generate antigenic diversity and form the basis of serotype classification (Sandström et al., 1982). P.II is exposed on the gonococcal surface, may play an important role in adhesion to epithelial cells (Lambden et al., 1979; James et al., 1980; Virji \& Everson, 1981) and shows antigenic heterogeneity. Different gonococcal strains each have the ability to produce up to six or more antigenically distinct P.II species (McBride et al., 1981; Swanson \& Barrera, 1983). Shift in expression of P.II occurs during natural infection and may enable gonococci to evade the consequences of the host immune response (Zak et al., 1984).

Although antibodies directed against P.I and P.II are opsonic, bactericidal and protect against gonococcal infection in model systems (Virji \& Heckels, 1986; Virji et al., 1986, 1987), the antigenic heterogeneity of these two major outer membrane proteins poses problems for vaccine development and has focused attention on more conserved proteins. P.III, the next most abundant outer membrane protein, is also surface-exposed, occurring in an association with the P.I porin complex which has not yet been fully defined. P.III appears to be highly conserved between strains (Judd, 1982) and is therefore a potential vaccine candidate. However, antibodies directed against P.III may exacerbate rather than protect against the pathogenic effect of gonococcal infection, in that antibodies to the protein when present in human sera may inhibit the bactericidal effect of those directed against P.I or lipopolysaccharide (Rice et al., 1986).

Abbreviations: OM, outer membrane; mAb, monoclonal antibody; PMN, polymorphonuclear leucocytes. 
Although the primary amino acid sequence of $P$.III has recently been determined (Gotschlich et al., 1987) little information is available on the surface immunochemistry of the protein and in particular whether antibodies directed against other P.III epitopes might protect against infection. In this report we describe the use of a panel of monoclonal antibodies to investigate the biological effect of antibodies directed against discrete P.III epitopes.

\section{METHODS}

Bacteria and outer membrane antigens. Strains of Neisseria gonorrhoeae, $N$. meningitidis and other Gram-negative bacteria used for screening the reactivities of monoclonal antibodies (mAbs) directed against P.III were identical to those previously used for screening mAbs against P.I (Virji et al., 1987). Outer membrane (OM) vesicles for immunization and for ELISA and Western blots were prepared by lithium acetate extraction (Heckels, 1977) of several different gonococcal strains. These included the P.IA-expressing strains SU62, SU70 and SU87, and the P.IB-xpressing strain P9. OMs from meningococcal strains MC50 and MC54 for use in Western blots were prepared in a similar manner.

Production of mAbs. Hybridomas described in this paper were obtained from a fusion of the NS-1 myeloma cell line and spleen cells derived from a BALB/C mouse immunized with a mixture of OMs from two gonococcal strains, SU62 and SU70. The immunization schedule and fusion protocol were essentially as described previously (Virji et al., 1987). Initial screening was done by ELISA using OMs from four gonococcal strains. Hybridomas which produced cross-reacting $\mathrm{mAbs}$ were further investigated by Western blotting (Virji et al., 1983) and those producing $\mathrm{mAbs}$ of interest were cloned by limiting dilution. High concentrations of mAbs were obtained by ascites production (Mueller et al., 1986). Ascitic fluids were either used directly or Ig was purified from them (Virji et al., 1987). The specificity of the cloned product was confirmed by several methods as described below.

Radioimmune precipitation (RIP) assay. Gonococci were harvested after $20 \mathrm{~h}$ growth on agar, and suspended at $2.5 \times 10^{9}$ c.f.u. $\mathrm{ml}^{-1}$ in Dulbecco's complete phosphate buffered saline (PBSB; Oxoid). For iodination, $40 \mu \mathrm{l}$ suspension was used in the presence of $2 \times 10^{-6} \mathrm{M}-\mathrm{KI}$ in a glass tube to which one iodobead (Pierce) and $200 \mu \mathrm{Ci}$ $(7.4 \mathrm{MBq}) \mathrm{Na}^{125} \mathrm{I}$ was added in a final volume of $50 \mu \mathrm{l}$. After incubation for $10 \mathrm{~min}$ at $15^{\circ} \mathrm{C}$, bacteria were recovered by centrifugation, washed with PBSB and labelled antigens were extracted in RIP buffer $[0.3 \%(v / v)$ Empigen (Albright and Wilson), 0.1\%(w/v) SDS, 0.05\% (w/v) sodium azide and $0 \cdot 1 \mathrm{mM}$-phenylmethylsulphonyl fluoride in PBS] as described by Zak et al. (1984). The specific activity of the solubilized protein was approximately $50-200 \mu \mathrm{Ci} \mathrm{mg}^{-1}\left(1.9-7.4 \mathrm{kBq}_{\mu \mathrm{g}}{ }^{-1}\right)$. Samples of the labelled antigen $\left(5 \times 10^{5} \mathrm{c} . \mathrm{p} . \mathrm{m}\right.$. in $\left.80 \mu \mathrm{l}\right)$ were reacted with $40 \mu$ ascitic fluids containing $\mathrm{mAbs}$. Serial tenfold dilutions of each $\mathrm{mAb}$ ranging from 1 in 10 to 1 in 10000 were used. Each sample was then mixed with $50 \mu \mathrm{l}$ goat anti-mouse IgG-agarose beads (Sigma) and rotated end-over-end for a further $1 \mathrm{~h}$ at $4^{\circ} \mathrm{C}$ then centrifuged at $10000 \mathrm{~g}$ for $2 \mathrm{~min}$. The beads were washed, boiled in dissociating buffer and samples of the supernatant solution $\left(10^{3}-10^{4}\right.$ c.p.m.) subjected to SDS-PAGE. Immunological reactivity was detected by autoradiography (Zak et al., 1984).

Western blotting of unreduced and reduction-modified P.III. OM preparations were boiled in the presence of dissociating buffer (Laemmli, 1970) with or without $10 \%$ (v/v) 2-mercaptoethanol. Both reduced and unreduced antigen preparations were subjected to SDS-PAGE in adjacent tracks. After electrophoretic transfer to nitrocellulose, the sheets were sequentially reacted with $\mathrm{mAbs}$ and ${ }^{125} \mathrm{I}$-labelled Protein $\mathrm{A}$ as previously described (Fletcher et al., 1986). For mAbs of $\gamma \mathrm{I}$ isotype, rabbit anti-mouse Ig (Sigma) was used before ${ }^{125} \mathrm{I}-$ labelled Protein A. Immunological reactivity was detected by autoradiography.

Reaction of $m A$ Abs with cloned P.III-gene product. Cell lysates of wild-type Escherichia coli and of recombinants containing the gonococcal P.III gene [a gift from Professor E. C. Gotschlich (Gotschlich et al., 1987)] were reacted with mAbs on Western blots as described above.

Dot-blot screening of bacterial strains for reactivity with P.III mAbs. A total of 100 Gram-negative bacterial strains comprising $50 \mathrm{~N}$. gonorrhoeae, $20 \mathrm{~N}$. meningitidis, $2 \mathrm{~N}$. lactamica, 12 commensal Neisseria, $10 \mathrm{E}$. coli and two each of Pseudomonas aeruginosa, Gardnerella vaginalis and Haemophilus influenzae were used. Standard bacterial suspensions were prepared containing approximately $1 \mathrm{mg}$ protein $\mathrm{ml}^{-1}$. Bacteria were lysed by freezing and thawing and $3 \mu \mathrm{l}$ of each lysate was applied to nitrocellulose sheets and air-dried. After blocking with $3 \%(\mathrm{w} / \mathrm{v})$ BSA, sheets were reacted with 1 in 1000 dilution of ascitic fluids containing mAbs. The antibody binding was detected with goat anti-mouse peroxidase conjugate and 4-chloro-1-naphthol as the substrate (Bio-Rad) or with ${ }^{125}$ I-labelled Protein A.

Radioimmunoassay and competitive binding experiments. OMs from gonococcal strain P9 were used to determine the binding parameters of P.III mAbs. Antigen-coated microtitre plates were reacted with serial dilutions of ${ }^{125} \mathrm{I}$ labelled purified Ig (Fletcher et al., 1986). The avidities of the $\mathrm{mAbs}$ and relative number of binding sites were determined from Scatchard plots as described by Frankel \& Gerhard (1979). Competitive binding of the P.III $\mathrm{mAbs}$ was investigated using pairs of antibodies. The inhibition of binding of ${ }^{125} \mathrm{I}$-labelled purified $\mathrm{Ig}$ (present at just saturating amounts) was determined in the presence of several concentrations of both homologous and heterologous unlabelled $\mathrm{mAbs}$. In addition, since P.I and P.III are closely associated in the OM, competition of 
binding in the presence of P.I-reactive mAbs was also studied. For this purpose, the cross-reacting mAbs SM101 (anti-P.IA) and SM24 (anti-P.IB) were used in conjunction with the OMs from appropriate P.IA- or P.IBexpressing strains. All assays were done in triplicate. The results were expressed as percentage inhibition of binding of ${ }^{125} \mathrm{I}$-labelled mAb (Fletcher et al., 1986).

Investigation of the potential biological roles of $\mathrm{mAbs}$. The efficacy of P.III $\mathrm{mAbs}$ in protection of host cells against gonococcal virulence was determined in an in vitro cytotoxicity assay using Chang conjunctiva epithelial cells, grown in monolayers (Virji \& Everson, 1981). The survival of tissue culture cells after challenge with gonococci in the presence or absence of $\mathrm{mAbs}$ was quantified by a safranin staining method (Virji \& Heckels, 1984). Both P.IAand P.IB-expressing strains were used, in separate experiments.

The bactericidal action of the $\mathrm{mAbs}$ was determined in the presence of $10 \%(\mathrm{v} / \mathrm{v})$ fresh normal human serum as the source of complement. In these assays, P.IA- and P.IB-expressing gonococcal strains resistant to $10 \%$ serum were used. Details have been previously reported (Virji et al., 1986, 1987).

The roles of mAbs in opsonization for phagocytosis by human polymorphonuclear leucocytes (PMN) was investigated by a luminol-enhanced PMN chemiluminescence assay (Virji et al., 1986, 1987). Both P.II- and P.II ${ }^{+}$ variants from gonococcal strain P9 (P.IB-expressing) were used, in addition to a P.II- variant from the P.IAexpressing strain SU70.

\section{RESULTS}

Specificity of $m A b s$. Several hybridomas were initially identified by Western blotting as producing possible P.III-reactive $\mathrm{mAbs}$, since they recognized antigens of apparent molecular mass in the range $30-33 \mathrm{kDa}$. Therefore, further investigations were made to identify any P.IIIreactive mAbs.

Radioimmunoprecipitation assays were done at a range of dilutions of ascitic fluids. The concentrations required for precipitation of antigens varied greatly, and a prozone was apparent with several mAbs. However, under optimum conditions, two bands of labelled antigens were obtained with six mAbs (SM50-SM55). With strain P9, one of the two bands corresponded to P.IB and the other had an apparent molecular mass of $31 \mathrm{kDa}$. Similarly, with strain SU87, coprecipitation of $P$.IA and the $31 \mathrm{kDa}$ antigen was observed. Co-precipitation of $P$.I with an antiP.III mAb has been previously observed (Swanson et al., 1982).

Additional evidence for the specificity of $\mathrm{mAbs}$ was obtained from their reaction with unreduced antigen (Fig. 1). P.III in the unreduced form migrates farther than the reduced antigen (McDade \& Johnston, 1980). On Western blotting the mAbs SM50-SM55 reacted with both the reduced antigen ( $31 \mathrm{kDa}$ band) and the unreduced antigen ( $30 \mathrm{kDa}$ band).

Finally, SM50-SM55 reacted with P.III produced by recombinant $E$. coli containing the gonococcal P.III gene but not with the wild-type E. coli (Fig. 2).

Properties of P.III mAbs. Table 1 lists several properties of the mAbs. Dot-blotting against whole-cell lysates showed similar patterns of reactivities: each $\mathrm{mAb}$ reacted with all pathogenic Neisseria strains and some commensal Neisseria strains, but with no other Gram-negative bacteria. Each $\mathrm{mAb}$ also reacted with the class 4 protein $(33 \mathrm{kDa})$ from OMs of two meningococci on Western blotting.

Competitive radioimmunoassay. The relationship between the epitopes on P.III recognized by the mAbs was investigated by competitive radioimmunoassay (Fig. 3). Each labelled mAb was effectively inhibited from binding to OMs of strain P9 by the presence of excess homologous unlabelled $\mathrm{mAb}$, but in every case by only one of the heterologous mAbs. Thus the six mAbs could be assigned to one of three pairs, SM50-SM51, SM52-SM53, and SM54-SM55, in which each member of a pair behaved similarly to and inhibited binding of the other. The mAbs were also tested for their ability under similar conditions to inhibit binding of $\mathrm{mAbs}$ directed against P.I. With OMs of strain P9 none of the anti-P.III mAbs showed significant inhibition of binding of antibody SM24, which recognizes a conserved epitope on P.IB (Fletcher et al., 1986). Similarly with OMs of strain SU87 no inhibition occurred in binding of antibody SM101, which recognizes a conserved epitope on protein IA (Virji et al., 1987).

Protection of epithelial cells. The protective effect of anti-P.III mAbs was studied using Chang conjunctiva epithelial cells in tissue culture which were challenged with gonococcal strains 

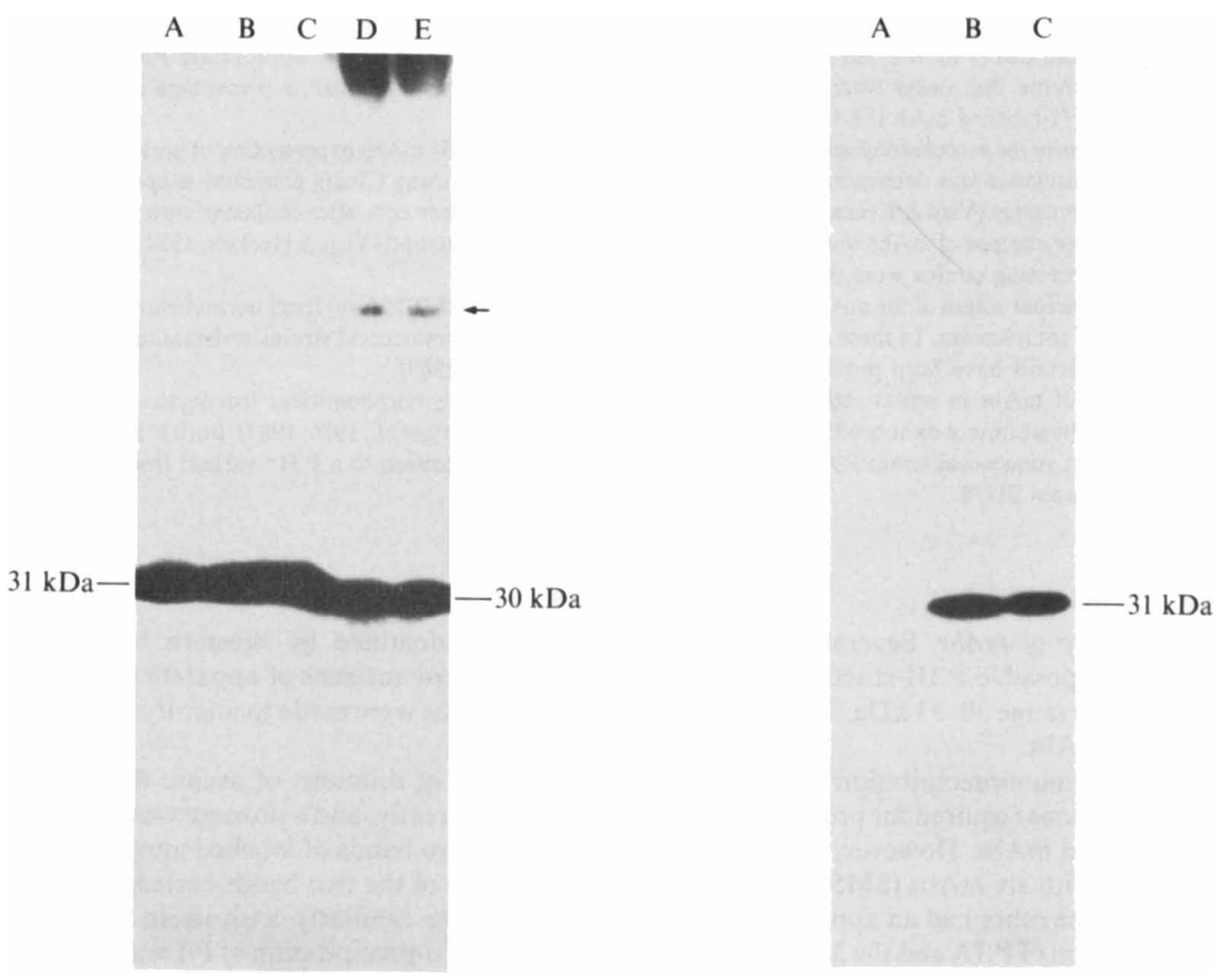

Fig. 1. Western blotting of unreduced and reduction-modified P.III with $m A$ b SM53. Reduced antigen was applied to tracks $A$ and $B$, and unreduced antigen to tracks $C, D$ and $E$; the apparent molecular mass of each is shown. Partial modification of the antigen due to diffusion of mercaptoethanol from adjacent track $B$ is apparent in track C. The arrowed band corresponds to unreduced P.I-P.III complex. Identical results were obtained with mAbs SM50-SM55.

Fig. 2. Reaction of $\mathrm{mAb}$ with cloned P.III gene product. Cell lysates of wild-type $E$. coli (track A), $E$. coli recombinants containing the gonococcal P.III gene (track B), and gonococcal strain P9 (track C) were reacted with mAb SM55 on Western blots. mAbs SM50-SM54 each reacted identically.

Table 1. Properties of anti-P.III mAbs

$\begin{array}{lccccc}\text { mAb } & \text { Isotype* } & \begin{array}{c}\text { Avidity } \dagger \\ \left(M^{-1}\right)\end{array} & \begin{array}{c}\text { Pathogenic } \\ \text { Neisseria }\end{array} & \begin{array}{c}\text { Commensal } \\ \text { Neisseria }\end{array} & \begin{array}{c}\text { Other } \\ \text { bacteria }\end{array} \\ \text { SM50 } & \gamma 2 \mathrm{a} & 4.1 \times 10^{8} & +(100) & \pm(33) & - \\ \text { SM51 } & \gamma 1 & 2.0 \times 10^{9} & +(100) & \pm(41) & - \\ \text { SM52 } & \gamma 1 & 1.2 \times 10^{9} & +(100) & \pm(25) & - \\ \text { SM53 } & \gamma 1 & 6.7 \times 10^{8} & +(100) & \pm(41) & - \\ \text { SM54 } & \gamma 2 b & 1.2 \times 10^{9} & +(100) & +(83) & - \\ \text { SM55 } & \gamma 2 \mathrm{a} & 1.5 \times 10^{9} & +(100) & +(33) & -\end{array}$

- Isotype was determined by ELISA using subclass-specific rabbit anti-mouse peroxidase conjugates (Zymed, Cambridge Bioscience).

† Avidities were estimated using ${ }^{125}$ I-labelled antibodies on OM-coated plates (Fletcher et al., 1986).

$\mp$ Reactivity was determined by dot-blotting against the panel of 100 organisms described in Methods: + , strong reaction; \pm , weak reaction; - no reaction (figures in parenthesis indicate percentage of strains reacting). 

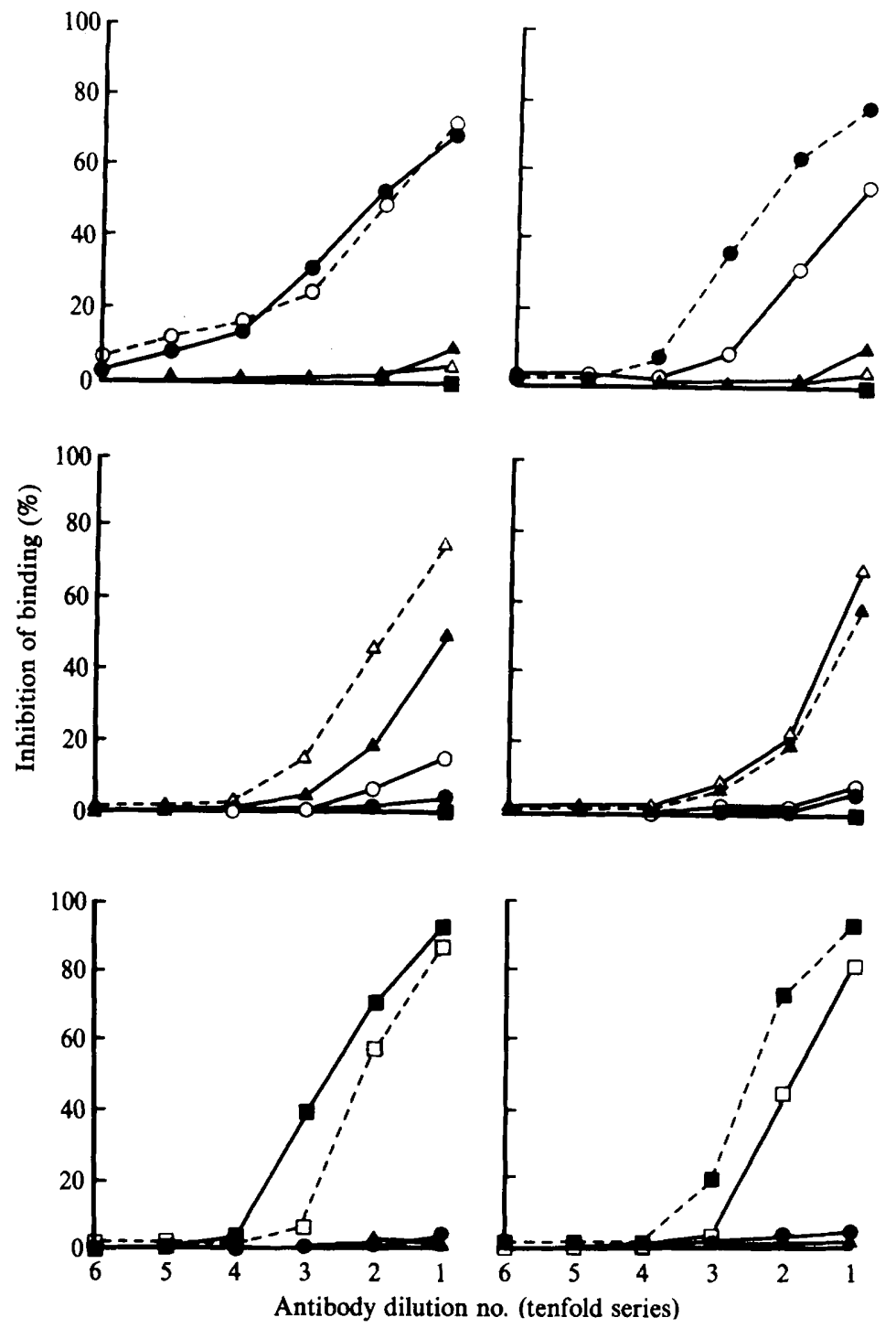

Fig. 3. Epitope analysis by competitive radioimmunoassay of anti-P.III mAbs. ${ }^{125}$ I-labelled mAbs $\left(0.5 \mu \mathrm{g} \mathrm{ml}^{-1}\right)$ were incubated in wells coated with OMs from strain P9 in the presence of serial tenfold dilutions of unlabelled mAbs. Dilution 1 represents $4 \mu \mathrm{g} \mathrm{ml}^{-1}$ of the competing Ig. Data are only plotted when inhibition of binding was observed; broken lines indicate homologous competition. Each $\mathrm{mAb}$ was used in competition against the labelled mAbs. O, SM50; , SM51; $\triangle$, SM52; $\Delta, S M 53 ; \square$, SM54; 口, SM55.

expressing either P.IA or P.IB (Table 2). Several of the mAbs protected tissue culture cells against gonococcal invasion, but to varying degrees: SM54 and SM55 were the most effective. Moreover, as for anti-P.I mAbs, greater protection against P.IB-expressing strains was apparent (Virji et al., 1987).

Bactericidal effect of P.III mAbs. Two of the six mAbs (SM50, $\gamma 2 \mathrm{a}$, and SM51, $\gamma 1$ ) were found to be non-bactericidal against the test gonococcal strains P9-2 (P.IB) and SU93 (P.IA) at all dilutions of mAbs tested (Figs 4 and 5). However, the rest of the mAbs which included $\gamma 1$ and $\gamma 2$ isotypes were very effective in this assay. One non-bactericidal mAb, SM50, was shown to fix complement by a complement fixation test using sensitized sheep erythrocytes (data not shown). 


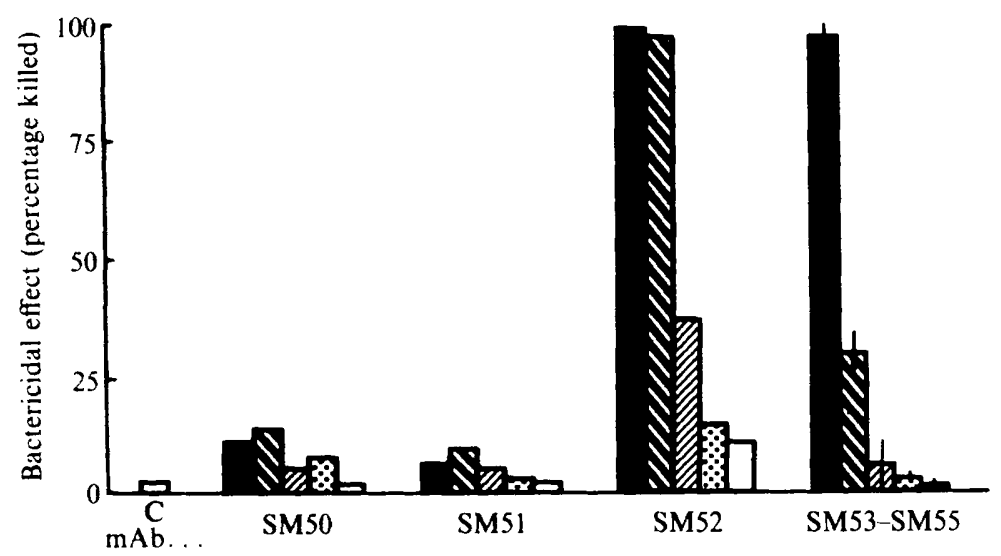

Fig. 4. Bactericidal action of anti-P.III mAbs on gonococcal strain P9 (expressing P.IB). Serial fivefold dilutions of ascitic fluid containing $m A$ bs were used in the presence of $10 \%(v / v)$ fresh human serum as a source of complement. The initial dilution of ascites was 1 in $\mathbf{4 0}(\mathbf{})$. Bactericidal activities of ascitic fluids containing SM53, SM54 or SM55 were comparable; these are presented together and the range is shown. C, control containing complement alone. Data are from one typical experiment; each estimation was done in triplicate (SD $< \pm 20 \%$ ).

Table 2. Protection of Chang conjunctiva epithelial cells in the presence of anti-P.III mAbs

\begin{tabular}{lcc} 
& $\begin{array}{l}\text { Relative increase in } \mathrm{LD}_{\text {so }} \dagger \\
\text { in the presence of } \mathrm{mAb}\end{array}$ \\
\cline { 2 - 3 } mAb* & $\begin{array}{c}\text { Challenge strain: } \\
\text { P9.IB) }\end{array}$ \\
SU62 (P.IA)
\end{tabular}

- Ascites dilution 1 in 100.

$\left\lceil\mathrm{LD}_{50}\right.$ with and without $\mathrm{mAbs}$ was determined after challenging Chang conjunctiva epithelial cells with different doses of gonococci. The figures represent the ratio of $L D_{50}$ in the presence of $m A b$ to that in the absence of $\mathrm{mAb}$.

Opsonization. None of the mAbs could be demonstrated by the chemiluminescence assay to opsonize any of the gonococcal strains tested. Typical results from one experiment are shown in Fig. 6. Assays also employed mAb dilutions ranging from 1 in 50 to 1 in 5000 both in the absence and the presence of $2 \%$ normal human serum as the complement source. Control samples in the same experiments containing an opsonizing antibody directed against P.I showed a significant increase in PMN chemiluminescence.

\section{DISCUSSION}

P.III of $N$. gonorrhoeae is a surface-exposed protein (Swanson et al., 1982) closely associated with the major OM protein I (P.I) (McDade \& Johnston, 1980; Newhall et al., 1980). It is universally expressed in all gonococcal strains regardless of the type of major OM protein expressed and is of identical apparent molecular mass (31 kDa) in gonococci (Judd, 1982). It is apparently closely related to the $33 \mathrm{kDa}$ class 4 protein of meningococci (Frasch et al., 1985). 


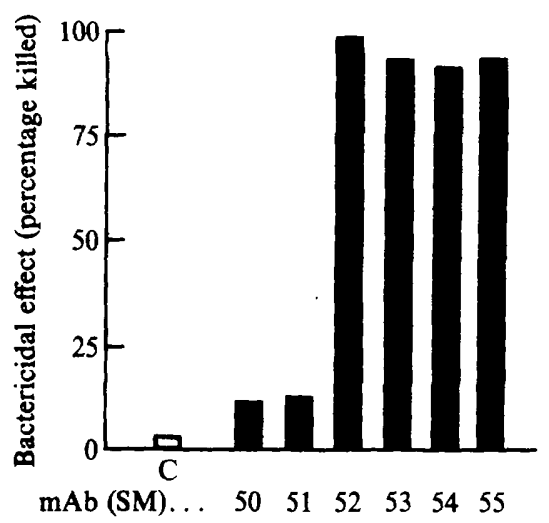

Fig. 5

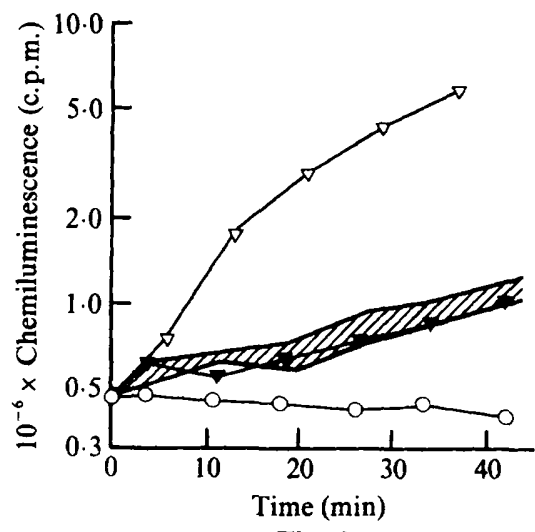

Fig. 6

Fig. 5. Bactericidal action of anti-P.III $\mathrm{mAbs}$ on gonococcal strain SU93 (expressing P.IA). Killing at the lowest dilution of ascites ( 1 in 40 ) is shown. Other details are given in legend to Fig. 4.

Fig. 6. Opsonization of gonococci (strain P9) with mAbs. The hatched area represents the range of chemiluminescence obtained in the presence of anti-P.III mAbs SM50-SM55 (present in ascites at 1 in 500 dilution). Controls contained PMN alone (O), PMN and gonococci without mAb ( $)$, or PMN and gonococci with the anti-P.IB mAb SM24 (V).

The structural conservation and its universal occurrence in $N$. gonorrhoeae may suggest an important functional role as yet unknown, for P.III. However, its proximity to the functionally important P.I has created recent interest in its immunological relationship with P.I.

In the current studies we have used six mAbs directed against gonococcal P.III in order to study the epitope distribution on P.III as well as the interactions of these mAbs with those directed against P.I.

That each of the epitopes recognized by the mAbs is surface-exposed was apparent from dot blots of whole-cell lysates. All the mAbs reacted with all the pathogenic Neisseria strains tested, and two reacted with some of the commensal Neisseria strains, but none reacted with $E$. coli or other Gram-negative bacteria. Thus surface-exposed immunogenic epitopes of gonococcal P.III are highly conserved in all pathogenic Neisseria species. Western blotting against OM proteins from two meningococcal strains confirmed that each mAb reacted with the class 4 protein of molecular mass $33 \mathrm{kDa}$ which appeared to be identical between the two strains.

Epitope analysis by competitive radioimmunoassay showed that each of the mAb pairs, SM50-SM51, SM52-SM53 and SM54-SM55, recognized one identical or two closely positioned epitopes. The level of inhibition between the pairs was low, demonstrating the presence of at least three distinct epitopes on the P.III molecule. The assays showed little competition of binding with P.I-reactive mAbs with the exception of SM50, which inhibited SM101 binding but only when present in gross excess (Virji et al., 1987).

Recent studies by Gotschlich et al. (1987) with the cloned P.III gene have revealed considerable similarities in the predicted amino acid sequence of the carboxy-terminal portion of P.III with the corresponding region of the $E$. coli OmpA protein. By analogy with the structure of OmpA the authors suggested a model in which only a small segment of P.III (residues 23-65) is available for exposure on the surface, with the remaining carboxy-terminal portion traversing the membrane and disposed in the periplasmic space. From this model at least three epitopes recognized by the mAbs in the current study must lie in this relatively small surface-exposed region.

Previous studies have shown that antibodies directed against OM proteins can exert a protective effect in three different in vitro model systems. Antibodies directed against P.I promoted complement-mediated bactericidal killing, were opsonic for phagocytosis by PMN 
and protected Chang epithelial cells from gonococcal challenge (Virji et al., 1986, 1987). Antibodies directed against P.III also exert a protective effect but these not only vary in the different model systems but are also dependent on the epitope recognized. Indeed, the observed biological effects appear to be dependent on the epitope recognized rather than the avidity of the antibody involved.

In the Chang cell model several of the anti-P.III mAbs were protective but the SM54-SM55 pair were clearly most effective. As with anti-P.I mAbs, protection was greater against P.IBexpressing strains than against P.IA-expressing strains, although the binding to each strain was similar. These observations are consistent with the suggestion that P.IA may impart greater virulence to gonococci by its greater ability to transfer to eukaryotic cell membranes (Blake, 1985).

In contrast, none of the anti-P.III mAbs showed opsonic activity and addition of complement had no further effect. One explanation may be that the number of antibody molecules bound is insufficient to bring about efficient attachment (our data show fewer numbers of P.III-reactive $\mathrm{mAb}$ molecules bound to OMs compared with P.I-reactive mAbs) or that their location is somehow unsuitable for effective PMN-gonococcal interactions.

$\mathrm{mAbs}$ directed against different epitopes of P.III also had different bactericidal activities. The two mAbs which bound to identical or closely positioned epitopes, SM50 and SM51, were non-bactericidal at all concentrations against several gonococcal strains from both P.IA- and P.IB-expressing groups. Despite its lack of bactericidal effect SM50 was shown to fix complement by a complement-fixation test, suggesting the importance of the location of the antibody-binding site in complement-mediated bactericidal activity. The other four mAbs, on the other hand, were very effective in this assay, demonstrating that at least two epitopes on P.III do elicit bactericidal antibodies. Previous studies by Rice et al. (1986) have suggested that anti-P.III antibodies in normal human serum block the bactericidal effect of antibodies directed against other surface antigens. A mAb directed against P.III also showed a similar effect (Rice et al., 1986). These antibodies, if complement-fixing, appear to be directed against epitopes similar to, or the same as, that (or those) recognized by SM50-SM51.

The relative importance of opsonic and bactericidal antibodies in protection against gonococcal infection is unclear but bactericidal antibodies may be particularly important in prevention of disseminated infection (Rice \& Goldenberg, 1981). Antibodies directed against some P.III epitopes are clearly bactericidal but any immunization strategy would have to be tailored to raise antibodies against protective epitopes while avoiding production of blocking antibody. The availability of $\mathrm{mAbs}$ combined with knowledge of the structure of P.III (Gotschlich et al., 1987) may now permit precise identification of both 'protective' and 'blocking' epitopes on the molecule.

This work was supported by an MRC Project Grant. We are grateful to Professor E. C. Gotschlich for the gift of the cloned P.III protein.

\section{REF ER E NCES}

BLAKE, M. S. (1985). Implications of the active role of gonococcal porins in disease. In The Pathogenic Neisseriae, pp. 251-258. Edited by G. Schoolnik. Washington, DC: American Society for Microbiology.

Douglas, J. T., LeE, M. D. \& Nikaido, H. (1981). Protein I of Neisseria gonorrhoeae outer membrane is a porin. FEMS Microbiology Letters 12, 305-309.

Fletcher, J. N., ZAK, K., VIRJI, M. \& Heckels, J. E. (1986). Monoclonal antibodies to gonococcal outer membrane protein $\mathrm{I}$ : location of a conserved epitope on protein I.B. Journal of General Microbiology 132, $1611-1620$

Frankel, M.E. \& Gerhard, W. (1979). The rapid determination of binding constants for antiviral antibodies by a radioimmunoassay. An analysis of the interaction between hybridoma proteins and influenza virus. Molecular Immunology 16, 101-106.

Frasch, C. E., Zollinger, W. D. \& PoOlman, J. T. (1985). Serotype antigens of Neisseria meningitidis and a proposed scheme for designation of serotypes. Reviews of Infectious Diseases 7, 504-510.

Gotschlich, E. C., SeifF, M. \& Blake, M. S. (1987). The DNA sequence of the structural gene of gonococcal protein III and the flanking region containing a repetitive sequence. Homology of protein III with enterobacterial OmpA proteins. Joumal of Experimental Medicine 165, 471-482. 
HeCkels, J. E. (1977). The surface properties of Neisseria gonorrhoeae: isolation of the major components of the outer membrane. Journal of General Microbiology 99, 333-341.

JAMES, J. F., LAMMEL, C. J., DRAPER, D. L. \& BROOKS, G. F. (1980). Attachment of $N$. gonorrhoeae colony phenotype variants to eukaryotic cells and tissues. In Genetics and Immunobiology of Pathogenic Neisseria, pp. 213-216. Edited by D. Danielson \& S. Normark. Umeå, Sweden: University of Umeå.

JUDD, R. C. (1982). ${ }^{125}$ I-peptide mapping of protein III isolated from four strains of Neisseria gonorrhoeae. Infection and Immunity 37, 622-631.

LAEMMLI, U. K. (1970). Cleavage of structural proteins during the assembly of the head of bacteriophage T4. Nature, London 227, 680-685.

LAMBden, P. R., Heckels, J. E., James, L. T.\& WATT, P. J. (1979). Variations in surface protein composition associated with virulence properties in opacity types of Neisseria gonorrhoeae. Journal of General Microbiology 114, 305-312.

LYNCH, E. C., BLAKE, M. S., Gotschlich, E. C. \& MAURo, A. (1984). Studies of porins: spontaneously transferred from whole cells of Neisseria gonorrhoeae and Neisseria meningitidis. Biophysical Journal 45, 109-117.

McBride, H. M., Lambden, P. R., Heckels, J. E. \& WATT, P. J. (1981). The role of outer membrane proteins in the survival of Neisseria gonorrhoeae P9 within guinea-pig subcutaneous chambers. Journal of General Microbiology 126, 63-67.

MCDADE, R. L. \& Johnstone, K. H. (1980). Characterisation of serologically dominant outer membrane proteins of Neisseria gonorrhoeae. Journal of Bacteriology 141, 1183-1191.

Mueller, U. W., Hawes, C. S. \& Jones, W. R. (1986). Monoclonal antibody production by hybridoma growth in Freund's adjuvant primed mice. Journal of Immunological Methods 87, 193-196.

Newhall, W. J., SAWYeR, V. W. D. \& HaAk, R. A. (1980). Cross-linking analysis of the outer membrane proteins of Neisseria gonorrhoeae. Infection and Immunity 28, 785-791.

Rice, P. A. \& Goldenberg, D. A. (1981). Clinical manifestations of disseminated infection caused by Neisseria gonorrhoeae and differences in bactericidal reactivity of infecting strains. Annals of Internal Medicine 95, 175-178.

Rice, P. A., VAYO, H. E., TAM, M. R. \& Blake, M. S. (1986). Immunoglobulin $G$ antibodies directed against protein III block killing of serum resistant Neisseria gonorrhoeae by immune serum. Journal of Experimental Medicine 164, 1735-1748.
SANDström, E. G., ChEN, K. C. S. \& Buchanan, T. M. (1982). Serology of Neisseria gonorrhoeae: co-agglutination serogroups WI and WII/III correspond to different outer membrane protein molecules. Infection and Immunity 38, 462-470.

Swanson, J. \& BARRERA, O. (1983). Gonoccal pilus subunit size heterogeneity correlates with transitions in colony piliation phenotype, not with changes in colony opacity. Journal of Experimental Medicine 158, 1459-1472.

Swanson, J. \& HeCkels, J. E. (1980). Proposal: nomenclature of gonococcal outer membrane proteins. In Genetics and Immunobiology of Pathogenic Neisseria, pp. xxi-xxvi. Edited by D. Danielson \& S. Normark. Umeả, Sweden: University of Umeä.

Swanson, J., MaYer, L. W. \& TAM, M. R. (1982). Antigenicity of Neisseria gonorrhoeae outer membrane protein(s) III detected by immunoprecipitation and Western blot transfer with a monoclonal antibody. Infection and Immunity 38, 668-672.

VIRJI, M. \& Everson, J. S. (1981). Comparative virulence of opacity variants of Neisseria gonorrhoeae strain P9. Infection and Immunity 31, 965-970.

VIRJI, M. \& HECKELS, J. E. (1984). The role of common and type-specific pilus antigenic domains in adhesion and virulence of gonococci for human epithelial cells. Journal of General Microbiology 130, 1089 1095.

VIRJI, M. \& HECKELS, J. E. (1986). The effect of protein II and pili on the interaction of Neisseria gonorrhoeae with human polymorphonuclear leucocytes. Journal of General Microbiology 132, 503-512.

VIRJ, M., Heckels, J. E. \& WATT, P. J. (1983). Monoclonal antibodies to gonococcal pili: studies on antigenic determinants on pili from variants of strain P9. Journal of General Microbiology 129, 19651973.

VIRJ, M., ZAK, K, \& Heckels, J. E. (1986). Monoclonal antibodies to gonococcal outer membrane protein IB: use in the investigation of the potential protective effect of antibodies directed against conserved and type-specific epitopes. Journal of General Microbiology 132, 1621-1629.

VIRJ, M., FletCher, J. N., ZAK, K. \& HeCkels, J. E. (1987). The potential protective effect of monoclonal antibodies to gonococcal outer membrane protein IA. Journal of General Microbiology 133, 2639-2646.

ZAK, K., DiaZ, J.-L., JACKSON, D. \& HeCKels, J. E. (1984). Antigenic variation during infection with Neisseria gonorrhoeae: detection of antibodies to surface proteins in sera of patients with gonorrhoea. Journal of Infectious Diseases 149, 166-173. 